\title{
Detection of driver mutations in FFPE samples from patients with verified malignant melanoma
}

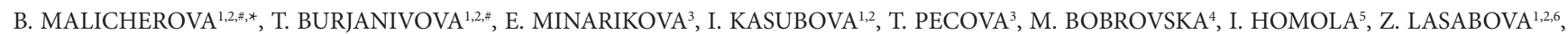 \\ L. PLANK $K^{1,2,4}$
}

${ }^{1}$ Biomedical Center Martin, Jessenius Faculty of Medicine in Martin, Commenius University in Bratislava (JFM CU), Slovakia; ${ }^{2}$ Division of Oncology JFM CU, Martin, Slovakia; ${ }^{3}$ Clinic of Dermatovenerology, Jessenius Faculty of Medicine and University Hospital in Martin, Martin, Slovakia; ${ }^{4}$ Department of Pathological Anatomy, Jessenius Faculty of Medicine and University Hospital in Martin, Martin, Slovakia; ${ }^{5}$ Department of Plastic Surgery, Jessenius Faculty of Medicine and University Hospital in Martin, Martin, Slovakia; ${ }^{6}$ Department of Molecular Biology, JFM CU, Martin Slovakia

${ }^{*}$ Correspondence: bibiana.malicherova@gmail.com

"Contributed equally to this work.

Received January 15, 2018 / Accepted April 24, 2018

\begin{abstract}
Malignant melanoma is an oncological disease characterized by etiologic heterogeneity and it has increasing incidence and mortality in the Slovak Republic. While it is treated surgically in combination with chemotherapy, targeted therapy, and immunotherapy, malignant melanomas can ulcerate and are susceptible to infections. These are highly aggressive cancers with metastasis, and recent studies have shown the presence of mutations in RAC1, PPP6C and STK19 genes in melanoma patients. Mutations in these genes are driver mutations; important in oncogenesis and providing selective advantage to tumor cells. The aim of our study is to establish a method to detect driver mutations in formalin-fixed, paraffin embedded (FFPE) tissue DNA. We applied Sanger sequencing to detect driver somatic mutations in RAC1, PPP6C, STK19 and BRAF genes in patients with malignant melanoma. Confirmation of BRAF V600E mutation was obtained by allele-specific PCR. The BRAF V600E mutation was present in 15 of 113 patients $(13.2 \%)$ and the driver mutation in 7 of 113 patients $(6.2 \%)$. Our results demonstrate that Sanger sequencing analysis detects mutations in FFPE clinical samples. The identification of these somatic driver mutations in samples with verified malignant melanomas enabled development of a molecular classification of melanomas, and our study provides evidence of diversity of novel driver mutations implicated in malignant melanoma pathogenesis. These findings could have very important implications for targeted therapy.
\end{abstract}

Key words: malignant melanoma, genetic analysis, driver mutations, diagnostic biomarker

The incidence of malignant melanomas has been increasing around the world, mainly in Caucasians. People with red hair and fair skin have a higher chance of developing melanoma. In the Slovak Republic, although malignant melanoma incidence is not high compared to other malignant tumors, it has relatively high mortality, especially when detected in advanced stages of the disease. The key risk factor for its appearance is exposure to UV radiation, so tumor may be prevented in predisposed people by avoiding direct sunlight and use of protective agents

Newer techniques of molecular biology improve the prognosis of the disease because these allow us to find genetic changes in nucleic acids, increase the specificity of diagnostic criteria and reduce time for patient diagnosis [1]. The exact mechanism for initiation of tumorigenesis of malignant melanoma is associated with constitutive activation of the mitogen-activated protein kinase pathway (MAPK). This is a complex signaling pathway with RAS/RAF proteins and other protein kinases including MEK and ERK. This pathway appears to be critical for the growth-phase of melanoma [2] and it is estimated that almost half malignant melanomas are associated with a MAPK activation mutation $[3,4]$.

A typical initiating oncogene involved in the MAPK pathway is a BRAF gene mutation (B-Raf Proto-Oncogene, Serine/Threonine Kinase). Over $60 \%$ of melanomas carry a $B R A F$ gene mutation, and $80 \%$ of these carry the BRAF V600E mutation $[5,6]$. For patients with metastatic melanoma and $B R A F$ V600E driver mutation, therapy targeting the mitogenactivated protein kinase pathway - a combination of BRAF inhibitors and MEK inhibitors - is an important treatment 
option [7]. The incidence of mutations in the BRAF and NRAS genes is significantly increased in skin melanomas not chronically exposed to UV radiation [8-12].

Other genes also have features which suggest a role in melanoma oncogenesis; three of these are protein phosphatase 6 catalytic subunit (PPP6C), Ras-related C3 botulinum toxin substrate 1 (RAC1) and serine/threonine kinase 19 (STK19). Mutations in STK19 (a predicted kinase with an unknown function) generally cluster around hot-spot regions, and subsequent somatic hotspot point mutations provide strong evidence that STK19 is a novel cancer gene in melanoma [12]. Activating mutations in RAC1 gene have been identified in $4 \%$ of all melanomas [12] and in $9 \%$ of sun-exposed melanomas [13].

RAC1 is a member of Rho family of small GTPases which have an important role in the control of cell proliferation and cell migration. The RAC1 gene is associated with the

Table 1. Clinical-pathological data of the cohort of 113 malignant melanomas, from the Department of Dermatovenerology, University Hospital in Martin, 62 men and 51 women, diagnosed in years 2015-2017.

\begin{tabular}{lc}
\hline Patients & $\begin{array}{c}\text { No. of patients } \\
\text { n=113(\%) }\end{array}$ \\
\hline Men & $62(54.8 \%)$ \\
Women & $51(45.1 \%)$ \\
Average age & \\
Men & $63.9(\mathrm{yr})$ \\
Women & $64(\mathrm{yr})$ \\
Types of melanoma & \\
Superficial spreading melanoma & $48(42.4 \%)$ \\
Nodular melanoma & $34(30.0 \%)$ \\
Acral lentiginous melanoma & $6(5.3 \%)$ \\
Lentigo malignant melanoma & $4(3.5 \%)$ \\
Unspecified type of melanoma & $9(7.9 \%)$ \\
Melanoma in situ & $9(7.9 \%)$ \\
Desmoplastic malignant melanoma & $1(0.88 \%)$ \\
Medium and late regression malignant melanoma & $1(0.88 \%)$ \\
Stage (pT) status, Thickness of malignant melanoma & \\
Tx $\quad$ unidentified & $3(2.6 \%)$ \\
T1 $\quad$ 0-1mm & $17(15.0 \%)$ \\
T2 $\quad$ 1,1-2,0 mm & $26(23.0 \%)$ \\
T3 2,1-4,0 mm & $45(39.8 \%)$ \\
T4 $\quad$ more than 4,1 mm & $22(19.4 \%)$ \\
Lymph node metastases status (pN) & \\
Nx & 1lymph node \\
N1 & $91(80.5 \%)$ \\
N2 2-3lymph nodes & $8(7.1 \%)$ \\
N3 4 lymph nodesmetastases & $9(7.9 \%)$ \\
Distant metastases status (pM) & $5(4.4 \%)$ \\
M1a Skin, subcutaneous tissue or & \\
M1b lymph nodes beyond the regional LU & $6(5.3 \%)$ \\
M1c $\quad$ Other localization & \\
Mx & \\
\hline & \\
&
\end{tabular}

assembly of actin filaments at the leading edge of cells [14], and it has recently been described as a common mutation in cutaneous melanomas together with BRAF and NRAS; and it is the third most frequent hotspot gain-of-function mutation in sun-exposed melanomas. RAC1 mutation is associated with UV damage [15] but a further newly discovered melanoma-associated gene is the $P P P 6 C$ potential tumor suppressor gene [12]. PPP6C encodes the catalytic subunit of the PP6 serine/threonine phosphatase complex. This gene has been reported to play an important role in several cancerrelated pathways, including de-phosphorylation of Aurora kinase A which regulates mitosis [16]. Results from both groups included $R 264 C$ mutations in $P P P 6 C$, thus indicating a tumor suppression function for this protein in melanoma [13]. PPP6C mutations may result in the loss-of-function typical for a tumor suppressor, and while PPP6C mutations occur in melanoma patient primary tumors and metastases, the cells with PPP6C mutations are sensitive to Aurora kinase inhibitors. This has therapeutic implications [16] because identification of mutations in cancer cells that drive malignant transformation may provide targeted therapy that improves overall survival [13].

\section{Patients and methods}

A total of 113 clinical samples of formalin-fixed, paraffin embedded tissue (FFPE) with malignant melanomas were included in this study; 85 were primary tumors and 28 were metastatic infiltrated lymph nodes. Melanoma samples were collected from 62 men and 51 women diagnosed in 2015-2017 (Table 1). Clinical-pathological information obtained from the patients with malignant melanoma are presented in Table 1 and Supplementary Table S1. All studied formalinfixed and paraffin embedded (FFPE) samples were collected from the archives of the Departments of Dermatovenerology and Pathology, University Hospital in Martin. The clinicalpathological data was extracted from the patient history. The lesion skin surface was examined in detail by dermatoscope and histological testing included basic immuno-histological examination (MelanA, HBM45, S100, VIM) [17]. Immunohistopathologic parameters including the extent of the tumor $(\mathrm{pT})$ and lymph node $(\mathrm{pN})$ and distant metastasis status (pM) were recorded (Table 1). Histological staging and grading was performed according to the revised pTNM classification of the American Joint Committee on Cancer (AJCC) and the Union for International Cancer Control (UICC) [18]. All participants enrolled in our study gave written informed consent and the study was approved by the Ethics Committee of University Hospital in Martin.

DNA extraction. DNA from paraffin embedded tissue was isolated by the black PREP FFPE DNA kit following the manufacturer's protocol. The optimized procedure included the extra step of de-paraffinisation and DNA was measured on NanoDrop ${ }^{\text {Tw }}$ 2000/2000C (Thermo Fisher Scientific, Germany). 
Table 2. Primer sequence, annealing temperature and length of the products used in this study.

\begin{tabular}{|c|c|c|c|c|}
\hline Gene & Primer & Sequence & Annealing temperature $\left({ }^{\circ} \mathrm{C}\right)$ & Product size (bp) \\
\hline \multirow{2}{*}{ PPP6C, exon 7} & Forward & F 5'-AAACTCATCTGCAGAGCACA & 58 & 271 \\
\hline & Reverse & R 5'-AAGAAGAGGGCAGAAAAATG & 58 & 271 \\
\hline \multirow{2}{*}{ STK19, exon 2} & Forward & F 5'-GACAAGTTGACGCTCCTTTC & 58 & 233 \\
\hline & Reverse & R 5'-AGAGGATCCGACTCCACAG & 58 & 233 \\
\hline \multirow{2}{*}{$R A C 1$, exon 2} & Forward & F 5'-TGTGATGTATATGCCTTGATTTT & 58 & 254 \\
\hline & Reverse & R 5'-AGCAAAACAAATGGTCAAAG & 58 & 254 \\
\hline \multirow{2}{*}{$B R A F$, exon 15} & Forward & F 5'-TGCTTGCTCTGATAGGAAAA & 58 & 204 \\
\hline & Reverse & R 5'-TCAGTGGAAAAATAGCCTCA & 58 & 204 \\
\hline
\end{tabular}

Mutational screening of BRAF, STK19, PPP6C, RAC1 by Sanger sequencing. Exon 15 of the $B R A F$ gene, exon 7 of PPP6C gene, exon 2 of Rac1 gene and exon 2 in theSTK19 gene were amplified by forward and reverse primers. All primer sequences are listed in Table 2. After PCR amplification, PCR products were purified by NucleoSpin Extract II kit (Macherey-Nagel, Germany) according to manufacturer instructions. The same set of primers was used for sequencing reactions. Sequencing of genes BRAF, PPP6C, Rac1 and STK19 was by BigDye Terminator v3.1 Cycle Sequencing kit (Applied Biosystems, Ca, USA) on the ABI PRISM 3130x1 automatic sequencer (Applied Biosystems, CA, USA) as previously described, and sequence data analysis was by Chromas software (http://www.technely-sium.com.au/chromas.html).

Allele-specific PCR for verification of BRAF V600E. We used allele-specific PCR for confirmation of V600E mutation in the BRAF gene. This assay was previously established in our laboratory and the allele-specific PCR for the BRAF V600E mutation was adopted from Jasek et al. [19].

Two primers (forward, 5'-TCATAATGCTTGCTCTGATAGGA-3'; reverse, 5'-GGCCAAAAATTTAATCAGTGGA-3'), as described previously, were used to amplify a $224 \mathrm{bp}$ fragment of exon 15 in BRAF containing the site where the T1799A mutation occurs.

Two different forward primers with substitution of a single base at the end of the primer (5'-GTGATTTTGGTCTAGCTACAGT-3' and 5'-TGATTTTGGTCTAGCTACAGA-3') were designed to amplify the wild-type allele or $B R A F$ T1799A transversion mutation, respectively. The sequence of the reverse primer was the same as used before and PCR products were evaluated on $1.5 \%$ agarose gel and separated by gel electrophoresis (Figure 1). Confirmation of BRAF V600E mutation was obtained by allele-specific PCR at ABI 3500 (Applied Biosystems, USA).

\section{Results}

Table 1 and Supplementary Table S1 summarize the clinical characteristics for 113 cases and their complete molecular screening results. Genes (STK19, PPP6C, RAC1 and BRAF) were evaluated in all samples by Sanger sequencing and only confirmed mutations were considered positive. BRAF V600E from all samples was verified by allele-specific PCR.
Clinical sample characteristics. We included 113 melanomas from 62 women and 51 men. The Mean age at diagnosis was 63.9 in males and 64 in females. The majority of melanomas (39.8\%) had Breslow thickness of 2.1-4.0 mm and $62.8 \%$ were tumor stage T2 $(\mathrm{n}=26)$, and T3 $(\mathrm{n}=45)$ (Table1). Most melanomas were superficial spreading melanomas (SSM) (48 of 113); thirty-four melanomas were nodular melanomas (ND); six were acral lentiginous melanoma (ALM); four were lentigo malignant melanoma (LMM); nine were unspecified type malignant melanomas (NS) and the in situ melanomas included one desmoplastic malignant melanoma (Table 1). Most melanomas were located on the back ( $\mathrm{n}=51,45.1 \%)$, followed by the upper limbs $(n=23,20.3 \%)$, lower limbs $(n=26,23 \%)$, the head, neck, ear and face $(n=12,10.6 \%)$. No mucosal melanomas were included in this study. Lymph node metastases status was positive in one lymph node ( $\mathrm{n}=8)$; in $2-3$ lymph nodes $(n=9)$ and in 4 lymph nodes or intra-nasal metastases $(n=5)$. Distant metastases were positive $(\mathrm{n}=6$, Table 1$)$.

Frequency of BRAF, STK19, PPP6C and RAC1 mutations in melanomas. In the prospective cohort of 113 patients, DNA was extracted from primary melanoma samples for mutation testing of genes PPP6C (exon 7), RAC1 (exon 2), STK19 (exon 2), BRAF V600E (exon 15); and included 28

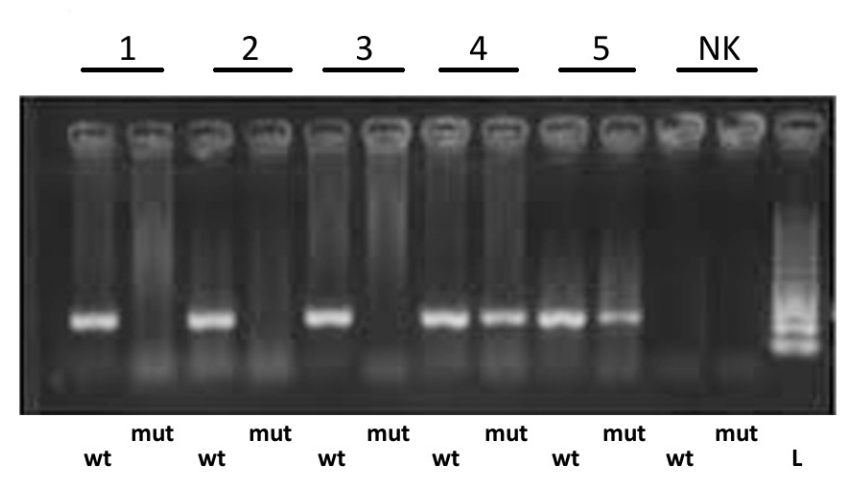

Figure 1. Allele-specific PCR for confirmation of BRAF V600E. Ladder marker (L), wild type (wt) from tissue (samples 1, 2, and 3), DNA from tissue isolated from patients with malignant melanoma carriers $B R A F$ V600E (samples 4, 5), sample without DNA (NK-negative control); (1.5\% agarose gel). PCR products were amplified with BRAF V600E specific primer in samples 4,5 . 
lymph node metastases. BRAF V600E mutations in exon 15 detected by Sanger-sequencing were present in $13.2 \%(n=15)$ of melanomas. The BRAF V600E mutation was confirmed in all cases using allele-specific PCR.

In the remaining 113 cutaneous melanomas, the RAC1 P29S mutation in exon 2 was detected in two samples (1.8\%) from all metastasis samples $(\mathrm{n}=28)$ and we also detected $B R A F$ V600E in primary melanoma in one patient with $R A C 1$ $P 29 S$. The median age of patients with RAC1 mutation was 75 years. Both patients harboring $R A C 1$ mutation were females (1.8\%). RAC1 mutant tumors were of nodular melanoma (NM) subtype, and RAC1 mutations had either ulceration or no ulcers (Supplementary Table S1).

Mutations in PPP6C, including the $R 264 C$ mutation in exon 7 , were found in $4 / 113$ patients (3.5\%). The $R 264 C$ mutation was detected in three patients with primary tumors and these were all BRAF V600E positive in primary and metastatic tissues. Only one patient had a $R 264 C$ driver mutation in metastases that was not present in the primary tumor. The median age of patients with PPP6C mutant melanoma was 60 years. PPP6C mutant tumors were of unspecified melanoma (NS), superficial spread melanoma (SSM) and nodular melanoma subtypes (NM - Supplemen-
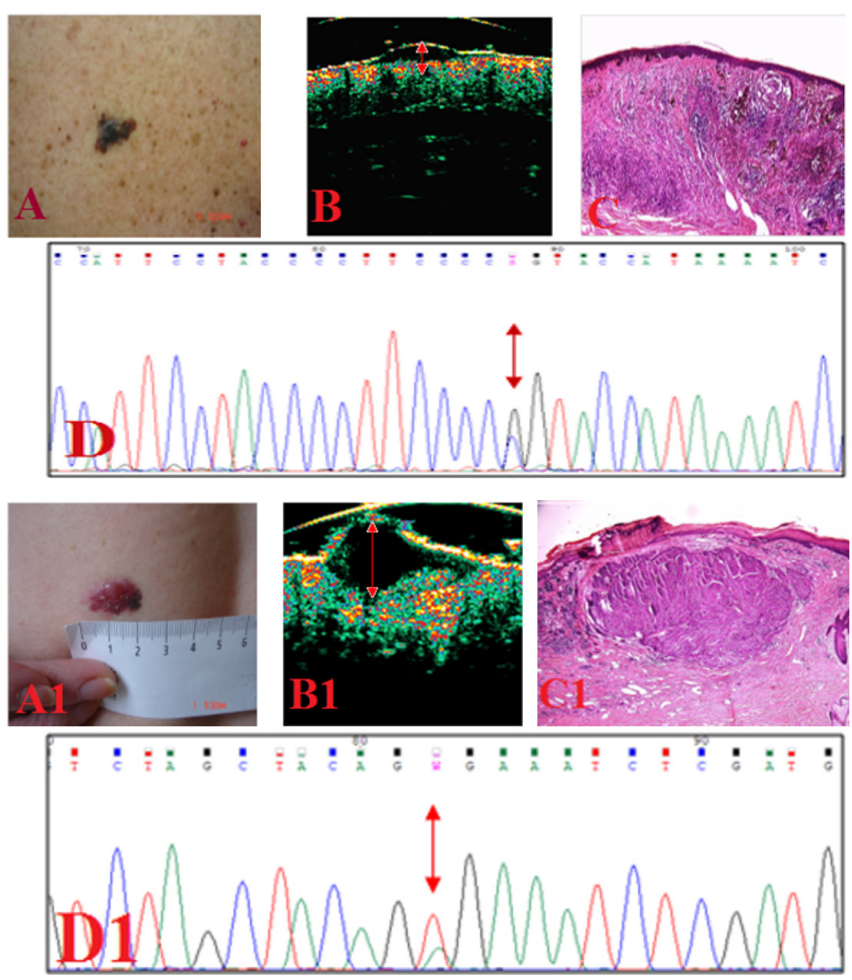

Figure 2. A, A1) Unspecified type of melanoma confirmed by sonography; B) Breslow 1.1 mm; B1) Breslow 2.8mm; C, C1) Immunohistochemical staining of hematoxylineosin. D) Sequencing of STK19 gene revealed $G 104 R$ variant. This mutation was also confirmed by sequencing with reverse primers (D1). Sequencing of BRAF gene revealed V600E mutation. This mutation was also confirmed by sequencing with reverse primers. tary Table S1). A variant in STK19 and G104R exon 2 was found in $1 / 113(0.9 \%)$ of patients; with the G104R variant detected in a primary tumor, so we used Variant Effect Predictor (Ensembl release 91-December 2017) to annotate this variant [20]. This $G 104 R$ variant was predicted, with low confidence, to be a deleterious variant; the patient was a 63-year-old male with unspecified melanoma and ulceration (Supplementary Table S1).

\section{Discussion}

Identification of somatic driver mutations in malignant melanomas has improved genetic status and classification. Herein, we evaluated the presence of RAC1, PPP6C, STK19, and $B R A F$ mutations. The most common BRAF mutation in malignant melanoma is the codon 600 valine to glutamate (V600E) substitution mutation [8]. We found 14 mutated samples from primary tumors and one from a metastatic lymph node which harbored BRAF V600E mutations, and we also recorded a previously unreported recurrent BRAF mutation in $R A C 1$ which resulted in a p.Pro29Ser substitution in 2 of the 113 tumors.

We therefore investigated the clinical and pathological associations of RAC1 P29S in this 113 malignant melanoma cohort with known BRAF mutation status. The RAC1 P29S mutation had $1.8 \%$ prevalence, increased Breslow thickness, greater mitotic activity, ulceration and nodular melanoma sub-type. The RAC1 P29S mutation was present in two melanomas; one in the patient's upper limb and the other on an ear. While this mutation was related to Breslow thickness [15], our study confirmed that RAC1 mutations occur more frequently in metastatic tissues (1.8\%). This was also proven in a study published by Mar et al. [15].

In the group of 113 samples (Tx-T4 tumors), two tumors were RAC1 mutated; T4 stage in one patient and $\mathrm{T} 2$ in another. The RAC1 P29S was significantly more prevalent in female patients compared to Krauthammer et al's findings where some sun-exposed RAC1 mutations were associated with males [13], but we found no evidence to support this gender association.

The activating mutation was associated with the nodular subtype in this cohort, similar to the report by Mar et al. [15]. RAC1 mutations have an important role in human malignancy and early tumor invasion, and we gound a genetic difference between primary and metastatic tumors in one patient who was tested for RAC1 and BRAF V600E mutations. BRAF V600E was found in that primary tumor, while $R A C 1$ was in the regional lymph node. This implies that $R A C 1$ has an important role in melanoma progression through metastatic regulation $[13,21,22]$.

The G104R variant in STK19 was identified in one patient $(0.9 \%)$ and this resulted in a p.Gly104Arg substitution of unspecified subtype. The STK 19 mutation was also present in one patient with $1.1 \mathrm{~mm}$ Breslow thick T2 stage primary tumor. Although there was low confidence in the predic- 
tion of this mutation as a deleterious variant [20], relevant discrepancy exists in variant classification using in-silico prediction tools [20].

The PPP6C R264C mutation in exon 7 resulted in a $\mathrm{p}$. Arg.264Cys amino-acid exchange, with $3.5 \%$ prevalence and increased mitotic activity. In this cohort, there were also 2 patients with ulceration, 2 with superficial melanoma spread subtype and 1 each with nodular melanoma and unspecified melanoma subtypes.

The PPP6C R264C mutation was present in four melanomas located on the trunk and upper and lower limbs, and occurred more frequently in patient primary tumors $3 / 113(2.7 \%)$ than in metastatic tissues $1 / 113(0.9 \%)$. Our findings agree with Gold et al. [16] who found four PPP6C mutated tumors; two patients with $\mathrm{T} 3$ stage and two patients with Tx and T2. Herein, we observed the co-existence of PPP6C and BRAF V600E mutations in the primary and metastatic tumors in one patient, and it is suggested that these two mutations cooperate in cancer development. Our results indicate clinical heterogeneity in PPP6C mutation positive tumors, and while there could be co-existence of sub-populations of cancer cells that differ in their genetic characteristics, Gold et al. did not find strong evidence of association between $P P P 6 C$ and $B R A F$ mutations in primary and metastatic tumors [16]. Our data indicate clinical heterogeneity in PPP6C mutation positive tumors.

The study shows that we can detect mutations which are potential targets for therapy in malignant melanoma patients. This can lead to optimization of on-going therapy and improved patient survival in this serious oncological disease [16]. Shitara et al. performed molecular analysis of 61 melanomas in 2015 by Sanger Sequencing of the BRAF, NRAS, C-KIT, PPP6C, STK19 and RAC1 genes [23], and found that mutations in $R A C 1$, including P29S, PPP6C, $S T K 19$, and BRAF, are more frequent in sun-exposed melanomas [23].

We also detected these gene mutations, although our samples were mostly composed of only intermittent sun-exposed melanomas on the trunk, upper and lower limbs and the ear. In contrast Shitara et al. found no mutations in RAC1, PPP6C, STK19 genes in melanomas associated with intermittent sun-exposed melanomas [23]. Further, our results indicate that allele-specific PCR is more sensitive than Sanger sequencing $[19,24]$, so we used allele-specific PCR to detect BRAF V600E mutation. We performed allele-specific PCR only on $B R A F$, because it had already been applied by Jasek et al. [19].

However, Sanger sequencing and allele-specific PCR have lower sensitivity than NGS, so NGS will most likely replace the less sensitive methods. The main disadvantage of NGS is the professional expertise required for comprehensive analysis and the interpretation of the resultant data [25]. In the near future, we plan to compare and correlate these results with liquid biopsy. Although this analysis may not always reflect the complete pattern due to tumor heteroge- neity, this very heterogeneity of melanoma cells enables the tumor to alter its microenvironment and escape therapeutic strategies. Histological examination still has an irreplaceable role in the diagnosis and management of cancer treatment, but liquid biopsy presents a milestone in personalized oncology because it can provide new benefits to patients with malignant melanoma and enable us to elucidate the molecular mechanisms involved in this serious disease.

Melanomas are heterogeneous malignant neoplasms, and despite recent insights into its genetics, further studies on driver mutations are required to improve knowledge of the genetic evolution of melanomas. This will aid melanoma classification and should reveal putative biomarkers and therapeutic targets. Finally, the study identified hotspot mutations in RAC1, STK19, PPP6C and BRAF genes in the tested melanoma samples and our combined results suggest that these genes have such an important role in melanoma pathogenesis that they should prove attractive therapeutic targets.

Supplementary information is available in the online version of the paper.

Acknowledgements: This work was supported by the Biomedical Center Martin (BioMed Martin) ITMS code 26220220187 project which is co-financed from EU sources and by the Slovak Research and Development Agency under the contracts no. APVV-16-0066 and no. APVV-14-0273.

\section{References}

[1] BALCH CM, BUZAID AC, SOONG SJ, ATKINS MB, CASCINELLI $\mathrm{N}$ et al. Final version of the American joint Committee on cancer staging system for cutaneous melanoma. https://doi.org/10.1200/JCO.2001.19.16.3635

[2] JUNKINS-HOPKINS J. Malignant melanoma: molecular cytogenetics and their implications in clinical medicine. J Am Acad Dermatol 2010; 63: 329-332. https://doi.org/10.1016/j. jaad.2010.04.044

[3] NIEZGODA A, NIEZGODA P, CZAJKOWSKI R. Novel Approaches to Treatment of Advanced Melanoma: A Review on Targeted Therapy and Immunotherapy. Biomed Res Int 2015; 2015: 851387. https://doi.org/10.1155/2015/851387

[4] SHAH DJ, DRONCA RS. Latest advances in chemotherapeutic, targeted and immuneapproaches in the treatment of metastatic melanoma. Mayo Clin Proc 2014; 89: 504-519. https://doi.org/10.1016/j.mayocp.2014.02.002

[5] DAVIES H, BIGNELL GR, COX C, STEPHENS P, EDKINS $S$ et al. Mutations of the BRAF gene in human cancer. Nature 2002; 417: 949-954. https://doi.org/10.1038/nature00766

[6] SMALLEY KS. Understanding melanoma signaling networks as the basis for molecular targeted therapy. J Invest Dermatol 2010; 130: 28-37. https://doi.org/10.1038/jid.2009.177

[7] SPAGNOLA F, GHIORZO P, ORGIANO L, PASTORINO L, PICASSO V et al. Onco Targets Ther 2015; 8:157-168. https://doi.org/10.2147/OTT.S39096 
[8] KUMAR R, ANGELINI S, CZENE K, SAUROJA I, HAHKA-KEMPPINEN $M$ et al. BRAF mutations in metastatic melanoma a possible association with clinical outcome. Clin Cancer Res 2003; 9: 3362-3368.

[9] LEE JH, CHOI JW, KIM YS. Frequencies of BRAF and NRAS mutation are different in histological types and sites of origin of cutaneous melanoma: a meta analysis. Br J Dermatol 2011; 164: 776-784. https://doi.org/10.1111/j.13652133.2010.10185.x

[10] ATKINSON V. Medical management of malignant melanoma. Aust Prescr 2015; 38: 74- 78.

[11] LUGOWSKA I, KOSELA-PATERCZYK H, KOZAK K, RUTKOWSKI P. Trametinib: a MEK inhibitor for managemet of metastatic melanoma. Onco Targets Ther 2015; 8: 2251-2259. https://doi.org/10.2147/OTT.S72951

[12] HODIS E, WATSON IR, KRYUKOV GV, AROLD ST, IMIELINSKI $\mathrm{M}$, et al. Landscape of driver mutations in melanoma. Cell 2012; 150: 251-263. https://doi.org/10.1016/j. cell.2012.06.024

[13] KRAUTHAMMER M, KONG Y, HA BH, EVANS P, BAC$\mathrm{CHIOCCHI} A$ et al. Exome sequencing identifies recurrent somatic RAC1 mutations in melanoma. Nat Genet 2012; 44: 1006-1014. https://doi.org/10.1038/ng.2359

[14] JAFFE AB, HALL A. Rho GTPases: biochemistry and biology. Annu Rev Cell Dev Biol 2005; 21: 247-269. https://doi. org/10.1146/annurev.cellbio.21.020604.150721

[15] MAR VJ, WONG SQ, LOGAN A, NGUYEN T, CEBON J et al. Clinical and pathological associations of the activating RAC1 P29S mutation in primary cutaneous melanoma. Pigment Cell Melanoma Res 2014; 27: 1117-1125. https://doi. org/10.1111/pcmr.12295

[16] GOLD HL, WENGROD J, DE MIERA EV, WANG D, FLEMING $\mathrm{N}$ et al. PP6C hospot mutations in melanoma display sensitivity to Aurora kinase inhibition. Mol Cancer Res 2014; 12: 433-439. https://doi.org/10.1158/1541-7786. MCR-13-0422
[17] BOBROVSKA M, MINARIKOVA E, PLANK L. [Diagnosis of melanoma]. Onkologia (Bratisl) 2009; 4: 144-148.

[18] SOBIN LH, WITTEKIND C. (Eds.). TNM classification of malignant tumors, 6th Edition. UICC-Wiley, New York 2002; p 264. ISBN 978-0-471-22288-0.

[19] JASEK K, BUZALKOVA V, MINARIK G, STANCLOVA A, SZEPE $P$ et al. Detection of mutations in the BRAF gene in patients with KIT and PDGFRA wild-type gastrointestinal stromal tumors. Virchows Arch 2017, 470: 29-36. https:// doi.org/10.1007/s00428-016-2044-4

[20] MCLAREN W, GIL L, HUNT SE, RIAT HS, RITCHIE GR et al. The Ensembl Variant Effect Predictor. Genome Bio. 2016; 17: 122. https://doi.org/10.1186/s13059-016-0974-4

[21] SANZ-MORENO V, GADEA G, AHN J, PATERSON H, MARRA $P$ et al. Rac activation and inactivation control plasticity of tumor cell movement. Cell 2008; 135: 510-523. https://doi.org/10.1016/j.cell.2008.09.043

[22] DALTON LE, KAMARASHEV J, BARNGA-REMENTERIE RAMIREZ I, WHITE G, MALLIRI A et al. Constitutive RAC activation is not sufficient to initiate melanocyte neoplasia but accelerates malignat progression. J Invest Dermatol 2013;133: 1572-1581. https://doi.org/10.1038/jid.2013.23

[23] SHITARA D, TELL-MARTI G, BADENAS C, ENOKIHARA MMSS, ALOS L et al. Mutational status of naevus-associated melanomas. Br J Dermatol 2015; 173: 671-680. https://doi. org/10.1111/bjd.13829

[24] PECOVA T, VORCAKOVA K, ZALIOVA M, BURJANINOVA T, MALICHEROVA B et al. Testicular cancer in Monozygotic Twin Brothers with Urticaria pigmentosa. Acta Derm Venereol 2018; 98: 528-529. https://doi. org/10.2340/00015555-2861

[25] BEHJATI S, TARPEY PS. What is next generation sequencing? Arch Dis Child Educ Pract Ed 2013; 98: 236-238. https://doi.org/10.1136/archdischild-2013-304340 


\section{Detection of driver mutations in FFPE samples from patients with verified malignant melanoma}

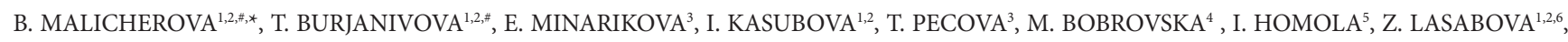
L. PLANK ${ }^{1,2,4}$

\section{Supplemental material}

Supplementary Table S1. Association between RAC1, STK19, PPP6C, BRAF with clinico-histopathological data.

\begin{tabular}{|c|c|c|c|c|c|c|c|c|c|}
\hline Case & Gender & Genes & $\begin{array}{l}\text { Mutations in genes } \\
\text { RAC1, PPP6C, STK19 } \\
\text { (Sanger seq.) }\end{array}$ & $\begin{array}{c}\text { BRAF V600E } \\
\text { (Sanger seq. + allele- } \\
\text { specific PCR) }\end{array}$ & Subtype & Localization & Breslow/Clark & TNM & $\begin{array}{l}\text { Mitotic } \\
\text { activity }\end{array}$ \\
\hline 12. $\mathrm{H}$ & Female & $R A C 1$ & $P 29 S$ in metastase & no & ND & Upper limbs & $5 \mathrm{~mm} /$ Clark IV & pT4a pNx pMx & $30 \mathrm{mf} / \mathrm{mm}^{2}$ \\
\hline 16. $\mathrm{H}$ & Female & $R A C 1$ & P29S in metastase & $\begin{array}{l}\text { BRAF V600E in pri- } \\
\text { mary tumor }\end{array}$ & ND & Ear & $2 \mathrm{~mm} /$ Clark IV & pT2a pNx pMx & $4 \mathrm{mf} / \mathrm{mm}^{2}$ \\
\hline 45. & Male & PPP6C & $\begin{array}{l}R 264 C \text { in primary } \\
\text { tumor }\end{array}$ & no & NS & Upper limbs & $2.6 \mathrm{~mm} /$ ClarkIV & pT3b pN0 pMx & $8-9 \mathrm{mf} / \mathrm{mm}^{2}$ \\
\hline 5.1 .0 & Female & PPP6C & $R 264 C$ in metastase & $\begin{array}{l}\text { BRAF V600E in } \\
\text { metastase }\end{array}$ & SSM & Trunk & $1.1 \mathrm{~mm} /$ ClarkIV & pTx pN2b pMx & $5 \mathrm{mf} / \mathrm{mm}^{2}$ \\
\hline 55. & Female & PPP6C & $\begin{array}{l}R 264 C \text { in primary } \\
\text { tumor }\end{array}$ & no & SSM & Lower limbs & $1.3 \mathrm{~mm} / \mathrm{ClarkIV}$ & pT2a pNx pMx & $11 \mathrm{mf} / \mathrm{mm}^{2}$ \\
\hline 12.1 & Male & PPP6C & $\begin{array}{l}R 264 C \text { in primary } \\
\text { tumor }\end{array}$ & $\begin{array}{l}\text { BRAF V600E in pri- } \\
\text { mary tumor }\end{array}$ & ND & Lower limbs & $3.1 \mathrm{~mm} /$ ClarkIV & $\begin{array}{c}\text { pT3a pNx } \\
\text { pMx }\end{array}$ & $8 \mathrm{mf} / \mathrm{mm}^{2}$ \\
\hline 76 & Male & STK19 & $\begin{array}{l}\text { G104R in primary } \\
\text { tumor }\end{array}$ & no & NS & Trunk & $1.1 \mathrm{~mm} /$ ClarkIII & pT2a pN0 pMx & $1 \mathrm{mf} / \mathrm{mm}^{2}$ \\
\hline 9. & Female & $B R A F$ & no & $\begin{array}{l}\text { BRAF V600E in pri- } \\
\text { mary tumor }\end{array}$ & ND & Lower limbs & $12 \mathrm{~mm} /$ Clark IV & pTx pNx pM1 & $4 \mathrm{mf} / \mathrm{mm}^{2}$ \\
\hline 21. & Female & $B R A F$ & no & $\begin{array}{l}\text { BRAF V600E in pri- } \\
\text { mary tumor }\end{array}$ & SSM & Upper limbs & $40 \mathrm{~mm} /$ Clark V & pT4b pNla pMx & $4-8 \mathrm{mf} / \mathrm{mm}^{2}$ \\
\hline 22. & Male & $B R A F$ & no & $\begin{array}{l}\text { BRAF V600E in pri- } \\
\text { mary tumor }\end{array}$ & ND & Lower limbs & $1.2 \mathrm{~mm} /$ Clark III & pT2a pNx pMx & $1 \mathrm{mf} / \mathrm{mm}^{2}$ \\
\hline 24. & Female & $B R A F$ & no & $\begin{array}{l}\text { BRAF V600E in pri- } \\
\text { mary tumor }\end{array}$ & NS & Trunk & $2 \mathrm{~mm} /$ Clark IV & pT2a pNx pMx & $4 \mathrm{mf} / \mathrm{mm}^{2}$ \\
\hline 25. & Female & $B R A F$ & no & $\begin{array}{l}\text { BRAF V600E in pri- } \\
\text { mary tumor }\end{array}$ & SSM & Lower limbs & $1.8 \mathrm{~mm} /$ Clark IV & pT2a pN0 pMx & $4 \mathrm{mf} / \mathrm{mm}^{2}$ \\
\hline 32. & Female & $B R A F$ & no & $\begin{array}{l}\text { BRAF V600E in pri- } \\
\text { mary tumor }\end{array}$ & ALM & Lower limbs & $\begin{array}{c}11.5 \mathrm{~mm} / \text { Clark } \\
\mathrm{IV}\end{array}$ & pT4b pN2c pMx & $15 \mathrm{mf} / \mathrm{mm}^{2}$ \\
\hline 47. & Male & $B R A F$ & no & $\begin{array}{l}\text { BRAF V600E in pri- } \\
\text { mary tumor }\end{array}$ & SSM & Trunk & $1.2 \mathrm{~mm} /$ Clark IV & pT2a pN0 pMx & $1 \mathrm{mf} / \mathrm{mm}^{2}$ \\
\hline 7.0 & Male & $B R A F$ & no & $\begin{array}{l}\text { BRAF V600E in pri- } \\
\text { mary tumor }\end{array}$ & SSM & Trunk & $3.1 \mathrm{~mm} /$ Clark IV & pT3a pNx pMx & $8 \mathrm{mf} / \mathrm{mm}^{2}$ \\
\hline 59. & Male & $B R A F$ & no & $\begin{array}{l}\text { BRAF V600E in pri- } \\
\text { mary tumor }\end{array}$ & SSM & Trunk & $3.9 \mathrm{~mm} /$ Clark IV & pT3a pNx pMx & $18 \mathrm{mf} / \mathrm{mm}^{2}$ \\
\hline 79. & Female & $B R A F$ & no & $\begin{array}{l}\text { BRAF V600E in pri- } \\
\text { mary tumor }\end{array}$ & ALM & Lower limbs & 3.9mm, Clark IV & pT3b pN2c pMx & $8-25 \mathrm{mf} / \mathrm{mm}^{2}$ \\
\hline 81. & Female & $B R A F$ & no & $\begin{array}{l}\text { BRAF V600E in pri- } \\
\text { mary tumor }\end{array}$ & NS & Trunk & $7.8 \mathrm{~mm} /$ Clark IV & pT3b pN0 pMx & $12 \mathrm{mf} / \mathrm{mm}^{2}$ \\
\hline 75. & Male & $B R A F$ & no & $\begin{array}{l}B R A F V 600 E \text { in pri- } \\
\text { mary tumor }\end{array}$ & ND & Lower limbs & $7.8 \mathrm{~mm} /$ Clark IV & pT4b pNx pMx & $20 \mathrm{mf} / \mathrm{mm}^{2}$ \\
\hline
\end{tabular}

F - Female; M - male; ND - nodular melonama; SSM - superficial spread melanoma; NS - unspecified melanoma; ALM - acral lentiginious melanoma; T2a, T3a - without ulceration; T3b, T4b - with ulceration. 